\title{
Video Article \\ Isolation and Expansion of Human Glioblastoma Multiforme Tumor Cells Using the Neurosphere Assay
}

\author{
Hassan Azari ${ }^{1,2}$, Sebastien Millette ${ }^{1}$, Saeed Ansari ${ }^{1}$, Maryam Rahman ${ }^{1}$, Loic P. Deleyrolle ${ }^{1}$, Brent A. Reynolds ${ }^{1}$ \\ ${ }^{1}$ Department of Neurosurgery, University of Florida \\ ${ }^{2}$ Department of Anatomical Sciences, Shiraz University of Medical Sciences
}

Correspondence to: Hassan Azari at Hassan.azari@neurosurgery.ufl.edu

URL: https://www.jove.com/video/3633

DOI: doi:10.3791/3633

Keywords: Neuroscience, Issue 56, Glioblastoma Multiforme, Tumor Cell, Neurosphere Assay, Isolation, Expansion

Date Published: 10/30/2011

Citation: Azari, H., Millette, S., Ansari, S., Rahman, M., Deleyrolle, L.P., Reynolds, B.A. Isolation and Expansion of Human Glioblastoma Multiforme Tumor Cells Using the Neurosphere Assay. J. Vis. Exp. (56), e3633, doi:10.3791/3633 (2011).

\section{Abstract}

Stem-like cells have been isolated in tumors such as breast, lung, colon, prostate and brain. A critical issue in all these tumors, especially in glioblastoma mutliforme (GBM), is to identify and isolate tumor initiating cell population(s) to investigate their role in tumor formation, progression, and recurrence. Understanding tumor initiating cell populations will provide clues to finding effective therapeutic approaches for these tumors. The neurosphere assay (NSA) due to its simplicity and reproducibility has been used as the method of choice for isolation and propagation of many of this tumor cells. This protocol demonstrates the neurosphere culture method to isolate and expand stem-like cells in surgically resected human GBM tumor tissue. The procedures include an initial chemical digestion and mechanical dissociation of tumor tissue, and subsequently plating the resulting single cell suspension in NSA culture. After 7-10 days, primary neurospheres of 150-200 $\mu \mathrm{m}$ in diameter can be observed and are ready for further passaging and expansion.

\section{Video Link}

The video component of this article can be found at https://www.jove.com/video/3633/

Protocol

\section{Collection of Primary GBM Tissue}

1. A glioblastoma mutliforme (GBM) tumor is obtained from a patient diagnosed with the cancer and undergoing surgery.

2. Arrangements must be made with neurosurgery team. The neurosurgeon will place the resected GBM tumor in an appropriate size tube containing neural stem cell (NSC) basal medium supplemented with $10-15 \%$ antibiotics (Peniciline/Streptomycine). Cold medium must be provided to operating room by lab. Alternatively, cold HEPES-buffered minimum essential medium (HEM) or phosphate buffered saline (PBS) with high concentration of antibiotics can also be used for this purpose.

3. The resected tumor tissue is delivered to the lab on ice and placed under the hood.

\section{Dissociation of Primary Tumor into Single-Cell Suspension}

1. Excess of the original medium/PBS is removed from the falcon tube and the sample is washed 2-3 times with $5-10 \mathrm{ml}$ of PBS/NSC basal medium to remove blood and debris. The PBS/Medium is removed and the GBM tumor tissue is placed in a Petri dish.

2. The tissue is cut into small pieces and minced with a No. 10 scalpel blade into tiny pieces to increase the surface area for trypsinization process. Mincing can take 1-3 minutes depending on the size of the tumor.

3. The minced tissue is trypsinized in $3-5 \mathrm{ml}$ of pre-warmed $\% 0.05$ trypsin-EDTA for $10-15$ minutes at a $37^{\circ} \mathrm{C}$ water bath. An electronic pipette is used to transfer the tiny tumor pieces and trypsin into a $15 \mathrm{ml}$ Falcon tube.

4. An equal volume of soybean trypsin inhibitor is added to stop the enzymatic trypsin reaction after the incubation period

5. Trypsin inactivation is ensured by pipetting the suspension up and down several times. Then, the suspension is pelleted down by centrifuging at $800 \mathrm{rpm}(110 \mathrm{~g})$ for $5 \mathrm{~min}$.

6. The supernatant is discarded and the tissue pieces are resuspended in $1 \mathrm{ml}$ of sterile NSC basal medium. The clumps are dissociated by gently pipetting up and down (3-7 times) until a smooth milky single cell suspension is achieved. The number of pipetting steps directly depends on the size of particles in the minced tissue. Lengthy and vigorous mechanical dissociation should be avoided as it might result in cell death and a reduction in sphere formation.

7. To remove un-dissociated pieces and debris, $10-15 \mathrm{ml}$ of basal medium is added to the tube and the cell suspension is filtered through a 40 micron cell strainer into a $50 \mathrm{ml}$ tube.

8. The filtered suspension is centrifuged at $800 \mathrm{rpm}(110 \mathrm{~g})$ for $5 \mathrm{~min}$. The supernatant is discarded afterwards. 
9. Pelletted cells are then resuspended in $1-2 \mathrm{ml}$ of complete NSC medium for cell counting.

\section{Cell Count and Plating}

1. $10 \mu \mathrm{L}$ of the cell suspension is added to $90 \mu \mathrm{L}$ of $0.04 \%$ Trypan blue in a $1 \mathrm{ml}$ eppendorf tube. Note: other appropriate cell dilutions may also be used.

2. Pipette up and down to mix the suspension. $10 \mu \mathrm{L}$ of the cells/trypan blue mixture is transferred to hemocytometer in order to count cell density.

3. Cells are plated in complete NSC medium (a mixture of NSC basal medium and NSC proliferation supplement at a 9:1 ratio) supplemented with $20 \mathrm{ng} / \mathrm{ml} \mathrm{EGF,} 10 \mathrm{ng} / \mathrm{ml} \mathrm{bFGF}$ and $1 \mu \mathrm{l} / \mathrm{ml}$ of $0.2 \%$ heparin $(2 \mu \mathrm{g} / \mathrm{ml})$ in appropriate tissue culture vessels. 5,20 and $40 \mathrm{ml}$ of medium is used for T25, T80 and T175 flasks, respectively. Antibiotics may be added to the medium at a concentration of 1:100 to decrease chance of contamination.

4. The flask is placed in an incubator set at $37^{\circ} \mathrm{C}$ and $5 \% \mathrm{CO}_{2}$.

\section{Passaging and expansion of GBM derived spheres:}

1. When the neurospheres reached an average size of $150-200 \mu \mathrm{m}$ in diameter, the culture is ready for subculture. The content of each flask is removed and placed in an appropriate size sterile tissue culture tube, and centrifuged at $800 \mathrm{rpm} \mathrm{(110} \mathrm{g)} \mathrm{for} 5 \mathrm{~min}$ at room temperature.

2. The supernatant is removed and the pellet is resuspended in $1 \mathrm{ml}$ of $\% 0.05$ trypsin-EDTA.

3. To achieve an optimal trypsinization, the cell suspension is incubated at $37^{\circ} \mathrm{C}$ in a water bath for $2-3$ min. To stop the trypsin activity an equal volume of soybean trypsin inhibitor is added to the cell suspension and the cell suspension is gently pipetted up and down.

4. The cell suspension is centrifuged at $800 \mathrm{rpm}(110 \mathrm{~g})$ for $5 \mathrm{~min}$. Then, the supernatant is removed and the cells are resuspended in $1 \mathrm{ml}$ of NSC medium.

5. A cell count is performed as described earlier.

6. The cells are plated at a concentration of $5 \times 10^{4}$ cells $/ \mathrm{ml}$ in complete NSC medium supplemented with growth factors and plated in appropriate size tissue culture vessels as described in previous part.

7. Secondary neurospheres are formed in $7-10$ days when incubated at $37^{\circ} \mathrm{C}$ in a humidified incubator with $5 \% \mathrm{CO}_{2}$.

\section{Representative Results:}

After plating the single cells harvested from GBM tumor tissue, tumor stem-like cells proliferate and generate small clusters of cells composed of few cells in 3-4 days (see the video and Figure 1). As these clusters grow, they acquire a more spherical shape so that by 7-8 days, proper phase bright spheres with an average diameter of 150-200 microns form (See the video and Figure 2). At higher magnification, healthy spheres usually demonstrate microspikes at their periphery. Having large sphere like clusters in 1-2 days after culture initiation is due to existence of non-dissociated clumps at the binging of the culture and should not be mistaken as true spheres. The amount of debris in primary tumor sphere culture varies depending on the initial source of tissue and whether or not it includes any surrounding brain tissue. Proper tissue preparation techniques including enzymatic and mechanical dissociation, and subsequent filtration of the sample with sufficient amount of medium can result in less debris in culture. 

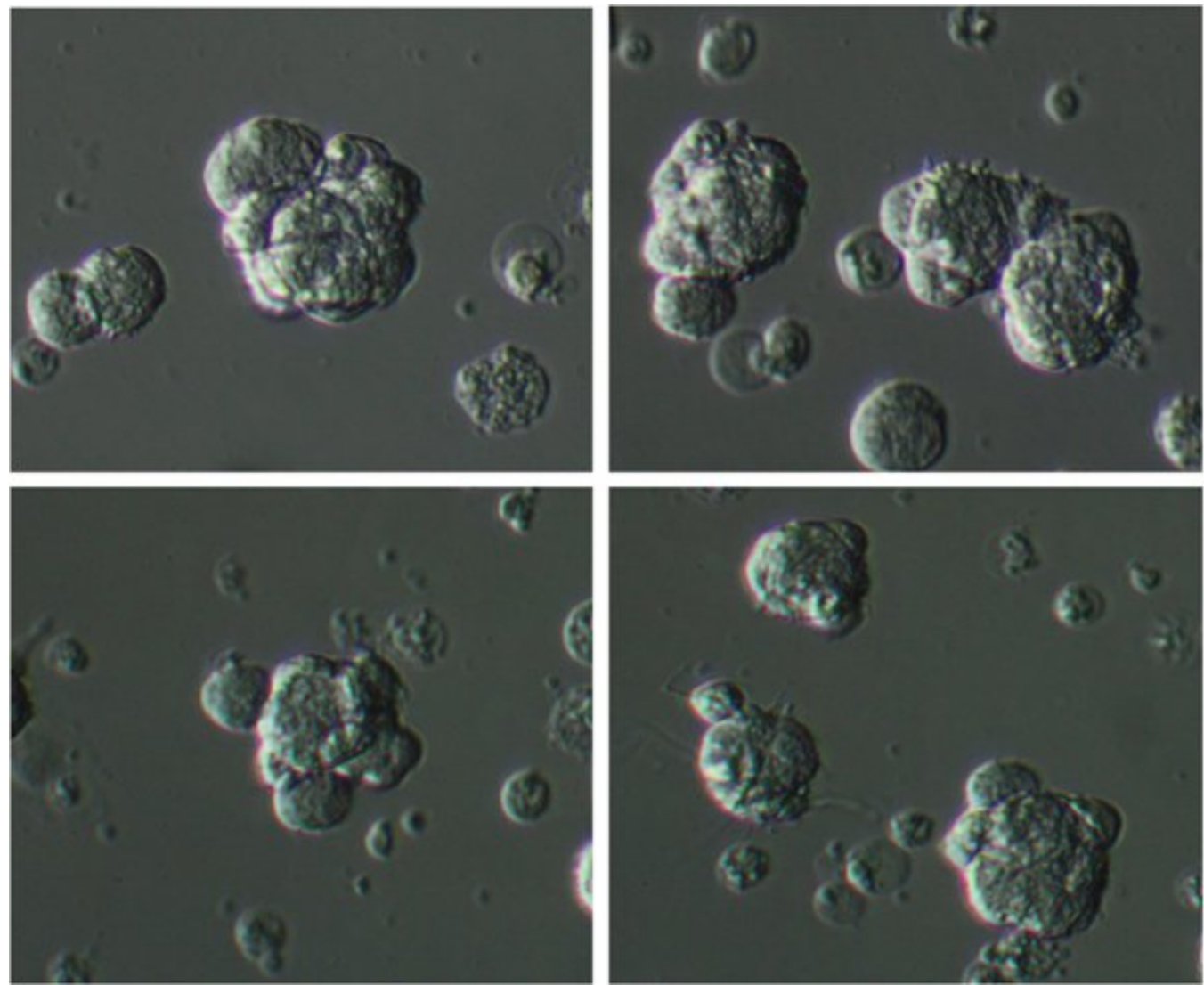

Figure 1. Primary GBM sphere culture 4 days after plating. Tumor stem-like cells proliferate and generate small clusters of cells in 3-4 days. Original Magnification; 20x.

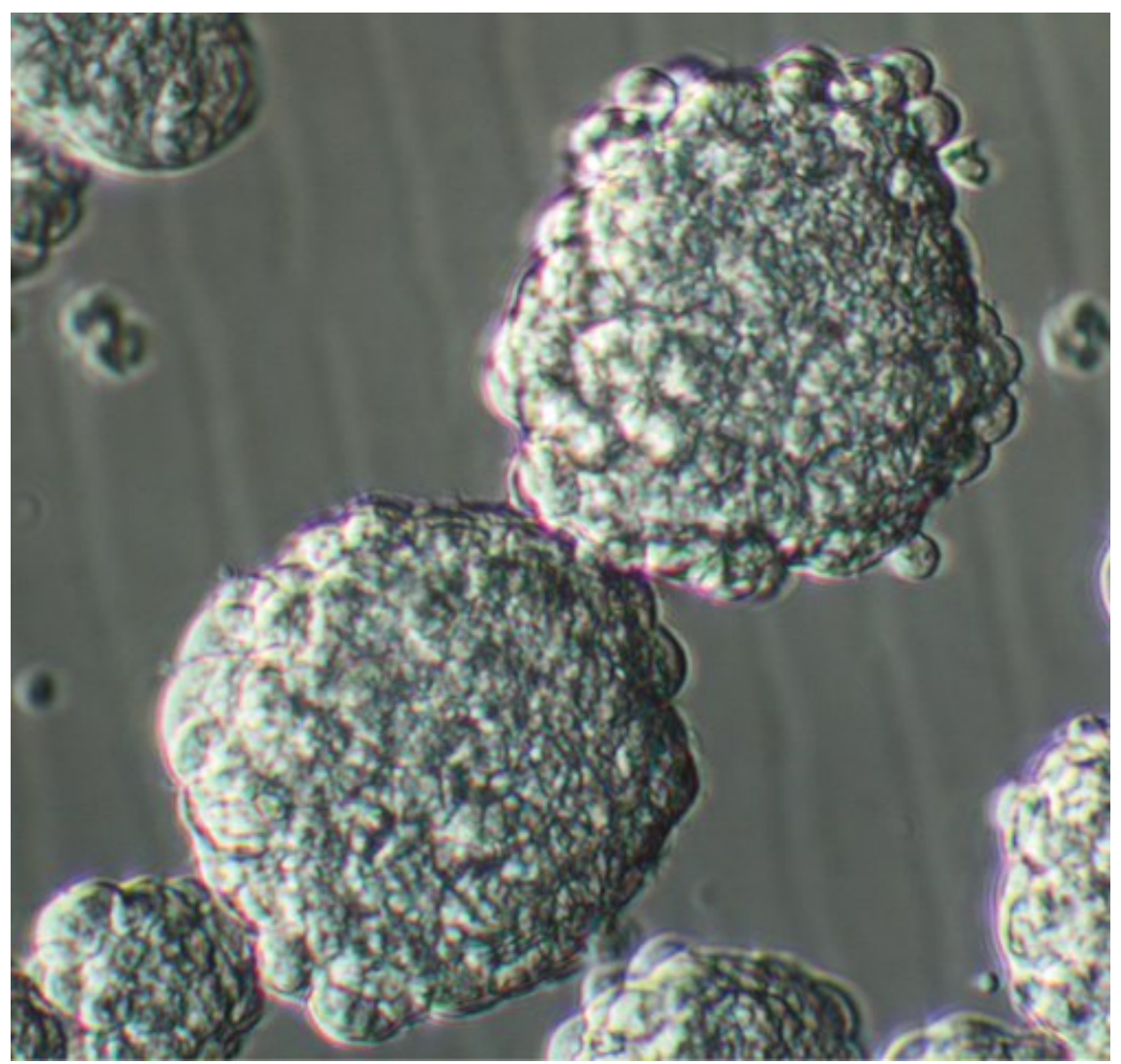


Figure 2. Passage one GBM sphere culture 8 days after plating. Original Magnification; 20x.

\section{Discussion}

To isolate neural stem and progenitor cells from normal adult and fetal brains ${ }^{1,2,3,4}$ and also tumor stem-like cells from cancer tissues such as lung ${ }^{5}$, prostate ${ }^{6}$, breast ${ }^{7}$ and brain ${ }^{8,9}$ the neurosphere assay has been frequently used as the method of choice. Using this simple and reproducible assay, one can generate an indefinite number of cells from resected tumor tissue that show similar characteristics as somatic stem cells; ex vivo multipotency, the ability to create new tumors upon implantation, and self-renewal. These cells could be used to study the basic cancer cell biology including cell-to-cell interactions, and differentiation, migration, invasion and cell death. In addition, isolated tumor stem-like cells provide an invaluable tool to study how tumors form, progress, and relapse and also to unravel the underlying deriving cellular mechanisms that eventually could provide insights to therapeutic options.

\section{Disclosures}

No conflicts of interest declared.

\section{Acknowledgements}

This work was supported by Grants from the Florida Centre for Brain Tumor Research; Preston A. Wells Jr. Center for Brain Tumor Therapy.

\section{References}

1. Reynolds, B.A. \& Weiss, S. Generation of neurons and astrocytes from isolated cells of the adult mammalian central nervous system. Science 255 (5052), 1707-1710 (1992).

2. Siebzehnrubl, F.A., Vedam-Mai, V., Azari, H., Reynolds, B.A., \& Deleyrolle, L.P. Isolation and Characterization of Adult Neural Stem Cells. Methods Mol Biol 750, 61-77 (2011).

3. Azari, H., Rahman, M., Sharififar, S., \& Reynolds, B.A. Isolation and Expansion of the Adult Mouse Neural Stem Cells Using the Neurosphere Assay. J. Vis. Exp. (45), e2393, DOI: 10.3791/2393 (2010).

4. Azari, H., Sharififar, S., Rahman, M. ., Ansari, S., Reynolds, B. A. Establishing Embryonic Mouse Neural Stem Cell Culture Using the Neurosphere Assay. J. Vis. Exp. (47), e2457, DOI: 10.3791/2457 (2011).

5. Eramo, A., et al. Identification and expansion of the tumorigenic lung cancer stem cell population. Cell Death Differ. 15 (3), $504-514$ (2008).

6. Patrawala, L., et al. Highly purified CD44+ prostate cancer cells from xenograft human tumors are enriched in tumorigenic and metastatic progenitor cells. Oncogene. 25(12), 1696-1708 (2006).

7. Li, X., et al. Intrinsic resistance of tumorigenic breast cancer cells to chemotherapy. J Natl. Cancer. Inst. 100 (9), $672-679$ (2008).

8. Galli, R., et al. Isolation and characterization of tumorigenic, stem-like neural precursors from human glioblastoma. Cancer Res. 64 (19), 7011-7021 (2004).

9. Deleyrolle, L.P., et al. Evidence for label-retaining tumour-initiating cells in human glioblastoma. Brain. 134 (Pt 5), 1331-1343 (2011). 